\title{
SAFER IS BETTER: Paving the Path for SAFe Consumption SITES IN INDIANA
}

\author{
ALEXIS WEAVER ${ }^{*}$
}

\section{INTRODUCTION}

David $^{1}$ was an outstanding musician. Whether on guitar, piano, ukulele, or harmonica, Dave could wail on them all. He was a voracious reader, animal lover, and unapologetic coffee snob. He possessed a fiery temper; one that would color his whole face and neck in a deep crimson and highlighted his freckles and bright, brown eyes. He had a quick smile and a quicker wit. And, he was seldom seen without a cigarette tucked behind his ear. Marlboro Reds: just one of a number of vices, most acquired too young.

Dave aspired to a career in music as his father had, dreaming to make a profession out of their shared passion. After his dad died, following a brief illness, he played with renewed ferocity and willed hours away, pouring over his father's unfinished compositions. His struggles with substance use also increased with unmitigated vigor. Yet, he projected his normal persona: sharp, bright, creative, and charming. He registered for college classes, started writing his own music, and even bought a new car.

A week after the purchase, he was found dead inside of it in an abandoned parking lot.

He was 26.

"An overdose is often a lonely way to die."

One of the most consistent patterns among the tens of thousands of national overdose deaths in recent years is that the victim's last moments went unobserved. ${ }^{3}$ This is because, often, with someone else present, the hallmark signs of an overdose - blue lips, restricted pupils, and loss of consciousness spurn witnesses to get help fast. ${ }^{4}$ When this happens, many overdoses can be reversed with tools such as Naloxone and prompt medical attention. ${ }^{5}$ Without intervention, the victim is left to die.

* J.D. / M.P.A. Candidate, 2021, Indiana University Robert H. McKinney School of Law; B.A., 2017, Indiana University-Purdue University Indianapolis, Indianapolis, Indiana.

1. The individual referred to as David or Dave was a personal friend. To maintain his privacy, his name has been changed for the purposes of this Note.

2. The Editorial Bd., Let Cities Open Safe Injection Sites, N.Y. Times (Feb. 24, 2018), https://www.nytimes.com/2018/02/24/opinion/sunday/drugs-safe-injection-sites.html [https://perma.cc/A9S5-YJXP].

3. Provisional Drug Overdose Death Counts, Nat'l Ctr. for Health Stat. (Mar. 11, 2020), https://www.cdc.gov/nchs/nvss/vsrr/drug-overdose-data.htm [https://perma.cc/R4FE-6XRV] (explaining that drug overdoses are often classified as "pending investigation[s]," while an official cause of death is determined).

4. Id.

5. Id. 
In 2017 , more than 1,800 people died as a result of a drug overdose in Indiana. ${ }^{6}$ Dave was among them. This number represents the highest number of drug overdose deaths ever recorded in the State at 29.4 per 100,000 residents. ${ }^{7}$ This figure also illustrates a $22 \%$ increase in overdose deaths since 2016 , awarding Indiana the grim third-place prize for the highest increase in overdose deaths in the nation over that single-year period. ${ }^{8}$

What the figure does not illustrate is the grief felt by those closest to the deceased. It does not account for the hours that parents drove around in cars, looking for their sons and daughters, hoping to find them before they overdosed alone on the streets. It does not observe the panic felt by spouses who found their partners and frantically administered Narcan, hoping this time was not the time. It does not take stock of the thousands of painful phone calls to friends and family, delivering the dreaded and devastating news. This was the call that I got. The call that too many of us get.

When you love someone who suffers from chronic substance use disorder, the reality that they may, as a result of their illness, join the ranks of the faceless, nameless statistics is a daily agony. This agony is compounded by the knowledge that such a death is not an unavoidable fate for those suffering from substance use disorder. These deaths are preventable.

Substance use disorders are part of a class of disorders listed in the Diagnostic and Statistical Manual of Mental Disorders, Fourth Edition that is characterized by "the taking of drugs of abuse (including alcohol)." ${ }^{.9}$ In 2014, 21.5 million Americans over the age of 12 , or roughly $8 \%$ of this population, experienced a substance use disorder within the prior year. ${ }^{10}$ About $30 \%$ of those substance use disorders were related to illicit drug use. ${ }^{11}$ Substance use disorders are diseases and are treatable. ${ }^{12}$ However, for so many, treatment resources and treatment facilities are inaccessible or nonexistent. ${ }^{13}$

6. Div. of Trauma \& Injury Prevention, Drug Overdose Epidemic in Indiana: Behind the Numbers, IND. St. DeP'T HeAlth 2 (Apr. 2019), https://www.in.gov/isdh/files/85_Drug\% 20Overdose\%20Data\%20Brief_2019.pdf [https://perma.cc/M7RW-KPWE].

7. $I d$.

8. Id.

9. Cristie Glasheen et al., Impact of the DSM-IV to DSM-5 Changes on the NATiOnAL SuRvey ON Drug USE AND HeAlth 5 (2016), https://www.ncbi.nlm.nih.gov/ books/NBK519697/pdf/Bookshelf_NBK519697.pdf [https://perma.cc/H9LJ-YA6S].

10. Sarra L. Hedden et al., Behavioral Health Trends in the United States: Results from the 2014 National Survey on Drug Use and Health 2 (2015), https://www. samhsa.gov/data/sites/default/files/NSDUH-FRR1-2014/NSDUH-FRR1-2014.pdf [https://perma.cc/A8KZ-JGEX].

11. Rachel N. Lipari \& Struther L. Van Horn, Trends in Substance Use Disorders Among Adults Aged 18 or Older, Substance Abuse \& Mental Health Serv. Admin. (June 29, 2017), https://www.samhsa.gov/data/sites/default/files/report_2790/ShortReport-2790.html [https://perma.cc/ZA72-V6D2].

12. Id.

13. Christine Vestal, Still Not Enough Treatment in the Heart of the Opioid Crisis, PEW 
Chronic illnesses are characterized by periods of remission and relapse. ${ }^{14}$ Substance use disorders are no different, and those suffering from them experience alternating periods of sickness and health just as with any other chronic disorder. ${ }^{15}$ Studies consistently and conservatively find that recurrence of symptoms - that is, periods of substance use - is experienced by over $85 \%$ of individuals suffering from substance use disorders. ${ }^{16}$ These statistics, though dismaying, are empowering: we know people with substance use disorders are going to experience periods of substance use, as part of the disease. This understanding is empowering because it gives policymakers and public health and safety officials a clear goal: reduce deaths associated with these periods of substance use.

Evidence-based findings clue policymakers into what can effectively reduce these overdose deaths: harm reduction strategies. Namely, such include safe spaces for people experiencing substance use disorders that do not criminalize or set unrealistic abstinence-only expectations.

This is where safe consumption sites come in.

\section{A. Roadmap}

This Note will aim to do three things. First, it will posit the public health need for the implementation of safe consumption sites by compiling the data on overdose deaths, the transmission of disease through unsafe substance use practices, and lack of access to treatment. This section will also showcase the economic costs of increasing rates of substance use disorder and its associated harms.

Second, it will give an overview of safe consumption sites, including the history of their implementation and efficacy abroad, the national landscape for the introduction of sanctioned sites in the United States, and recent developments regarding the legal status of these sites.

The final portion of this Note will endeavor to analyze the path forward for the establishment of a site in Indiana. This section will dissect existing Indiana Code provisions to (1) propose how a safe consumption site could be piloted; (2) suggest changes to the Code to fully realize the legal establishment of a site; (3) critique other existing Indiana drug law that would hinder efforts to establish and maintain a site; and (4) propose a strategy for advocacy for the creation of a pilot site as a vital public health necessity.

Charitable TR. (Sept. 26, 2016), https://www.pewtrusts.org/en/research-and-analysis/blogs/ stateline/2016/09/26/still-not-enough-treatment-in-the-heart-of-the-opioid-crisis [https://perma.cc/H3Q2-AFJV].

14. William L. White \& A. Thomas McLellan, Addiction as a Chronic Disorder: Key Messages for Clients, Families and Referral Sources, 9 Couns. 24, 30 (2008).

15. Id.

16. Rajita Sinha, New Findings on Biological Factors Predicting Addiction Relapse Vulnerability, 13 CURRENT PSYCHIATRY REP. 398, 398 (2011). 


\section{AN ISSUE OF PUBLIC HEALTH}

The perception of substance use as a moral failing has prevented efficacious treatment of what science has shown us, for decades, is a disease. ${ }^{17}$ The ongoing opioid crisis is often framed as a new epidemic, when, in actuality, we are merely experiencing the latest wave of an ongoing and decades-long problem of opioid and other substance abuse in America. ${ }^{18}$ The trends in Indiana opioid-related deaths have followed the similar three-wave pattern experienced nationally. Wave 1 in the 1990s was primarily driven by prescription opioid deaths. ${ }^{19}$ Wave 2 in the mid- to late-2000s was characterized by a significant increase in heroin overdose deaths. ${ }^{20}$ Wave 3 , corresponding to the current crisis narrative, began around 2014 and has been stimulated by a dramatic rise in synthetic opioid overdose deaths that are primarily fentanyl-related. ${ }^{21}$ While the most recent wave of overdose deaths presents its own unique political and public health challenges, and as public health and safety officials scramble to figure out how to confront and stem the flow of deadly illicit fentanyl into the market, ${ }^{22}$ these symptoms are emblematic of a greater underlying problem: how we confront and treat substance use disorders broadly.

Historically, the United States has approached substance use mitigation efforts primarily through the criminalization of drug use and possession. ${ }^{23}$ However, over a decade of evidence-based data shows that rather than mitigating substance use and associated overdose deaths, criminalization as a primary strategy actually exacerbates the problem by creating barriers to health and treatment for people with an opioid use disorder. ${ }^{24}$ According to Human Rights

17. See Nora D. Volkow \& Joanna S. Fowler, Addiction, a Disease of Compulsion and Drive: Involvement of the Orbitofrontal Cortex, 10 CEREBRAL CORTEX 318 (2000) (analyzing addiction as a disease).

18. Opioid Data Analysis and Resources, Ctr. for Disease Control \& Prevention, https://www.cdc.gov/drugoverdose/data/analysis.html [https://perma.cc/2ABN-PU2W] (last updated Mar. 19, 2020).

19. Understanding the Epidemic, CTR. FOr Disease COntrol \& Prevention, https://www.cdc.gov/drugoverdose/epidemic/index.html [https://perma.cc/9RZB-3RUL] (last updated Mar. 19, 2020).

20. Id.

21. Div. of Trauma \& Injury Prevention, supra note 6, at 3.

22. Caroline Carney, 4 Strategies for Combatting the Third Wave of the Opioid Epidemic: Fentanyl, AM. J. MANAGED CARE (June 13, 2019), https://www.ajmc.com/contributor/carolinecarney/2019/06/4-strategies-for-combatting-the-third-wave-of-the-opioid-epidemic-fentanyl [https://perma.cc/E5PQ-D9R2].

23. Christopher J. Coyne \& Abigail R. Hall, Four Decades and Counting: The Continued Failure of the War on Drugs, CATO INST. (Apr. 12, 2017), https://www.cato.org/publications/ policy-analysis/four-decades-counting-continued-failure-war-drugs [https://perma.cc/U7LN-7T9Z].

24. Human Rights Watch, Every 25 Seconds: The Human Toll of Criminalizing Drug Use IN THE United States 165 (2016). 
Watch, criminalization drives drug use underground; it discourages access to emergency medicine, overdose prevention services, and risk-reducing practices such as syringe exchanges. ${ }^{25}$ When these barriers are erected on a systematic basis, there can be little surprise when overdose deaths soar.

Recognition of substance use disorder as a disease, rather than a criminal act, can begin to dismantle those barriers. Rather than setting impossible and unrealistic standards, policymakers need to get serious about combatting increasing overdose death rates and embrace one of the few proven methods of improving quality and quantity of life for those suffering from substance use disorder: harm reduction. ${ }^{26}$

\section{A. Data on the Public Health Impact}

In 2017 , the last year for which we have national publicly available data, more than 70,000 Americans died of an accidental drug overdose. ${ }^{27}$ This staggering number represented nearly a $10 \%$ increase in national accidental drug overdose deaths from only the year before, ${ }^{28}$ signifying the ongoing nature of the public health crisis related to substance use disorder. Indiana deaths outpaced both the national average of overdose deaths per capita and the year-to-year increase from 2016 to $2017 .^{29}$

In Marion County, specifically, a more nuanced and up-to-date data set is available. The Indiana University Public Policy Institute's Center for Health and Justice Research was able to "combine death reports, toxicology reports, and information from police reports to provide a more holistic view of the circumstances surrounding a person's death" and to determine what substances and usage practices were contributing to overdose deaths. ${ }^{30}$ This review found that of the 361 overdose deaths in Marion County in 2018, those resulting from heroin and prescription opioids were down slightly from 2017. However, those deaths attributable to methamphetamine and cocaine were up. ${ }^{31}$

Alarmingly, accidental overdose deaths, which involved fentanyl, were significantly higher than in 2017 , and fentanyl was a contributor in $54 \%$ of all

25. Id.

26. Nathaniel Gunn et al., Primary Care as Harm Reduction for Injection Drug Users, 280 JAMA 1191, 1191 (1998).

27. Drug Overdose Deaths, Opioid Overdose, Ctr. for Disease Control \& Prevention, https://www.cdc.gov/drugoverdose/data/statedeaths.html [https://perma.cc/9QJU-P3NR] (last updated Mar. 19, 2020).

28. Div. of Trauma \& Injury Prevention, supra note 6.

29. Id.

30. New Numbers Show Drop in Overdose Deaths in Marion County, Ind. UnIV. Pub. PoL'y INST. (July 18, 2019), https://policyinstitute.iu.edu/news-media/stories/overdose-deaths-2019.html [https://perma.cc/JV4D-DVVV].

31. Leslie Wells, CHJR Researchers Examine Drug Overdose Deaths in Marion County, InD. UNIV.-PURDUE UNIV. INDIANAPOLIS (July 22, 2019), https://blog.oneill.iupui.edu/2019/07/22/2018overdose-deaths/ [https://perma.cc/6ECT-4MRW]. 
Marion County accidental overdose deaths. ${ }^{32}$ This type of information can clue public health officials in on the spike in fentanyl-laced illicit drugs being introduced in Marion County. Such public health data is crucial to arming harm reduction coalitions with the proper and effective supplies, such as more fentanyl testing kits.

Public health is not merely impacted by the number of accidental overdose deaths that result from inadequate community responses to the needs of people with substance use disorders. The morbidities associated with substance use also greatly impact public health at large. One of the most obvious ways this is borne out is in the elevated rates of infectious disease transmission driven by the sharing of needles and other equipment during intravenous drug use.

Both of these are critical data points in developing a strategy to reduce the mortalities and morbidities associated with substance use disorder. They inform public health professionals on what is critically needed: (1) equipment to help screen for deadly fentanyl contamination, and (2) sterile and safe equipment. The next question is how to distribute these tools to this vulnerable population when doing so can cause criminal consequences for this already highly stigmatized and marginalized group.

When access to sterile equipment and spaces needed for safe substance use is denied to people with substance use disorders, or when access to such resources is criminalized, it has no effect on reducing substance use. ${ }^{33}$ Rather, it has the inverse effect of increasing unsafe substance use that contributes to increased overdose deaths and disease transmission. ${ }^{34}$

The Centers for Disease Control and Prevention are clear on the measurable impact of substance use related to intravenous drug use, saying "injection drug use ... is a risk factor for contracting blood-borne pathogens such as HIV and [hepatitis C], and sharing syringes provides a direct route of transmission for diseases." ${ }^{35}$ Intravenous drug use is the most common means of hepatitis $\mathrm{C}$ transmission in the United States. ${ }^{36}$ Fully, one-third of people ages 18 to 30 who inject drugs are hepatitis C-positive. ${ }^{37}$ Intravenous drug use is attributable to thousands of new diagnoses of HIV infection each year. ${ }^{38}$ In 2017, Marion County saw a " 10 -fold increase" in new hepatitis $\mathrm{C}$ cases. ${ }^{39}$ Of those cases, $86 \%$

32. $I d$

33. Human Rights Watch, supra note 24.

34. Id.

35. Access to Clean Syringes, CTR. For Disease Control \& Prevention, https://www.cdc. gov/policy/hst/hi5/cleansyringes/index.html [https://perma.cc/Y9GY-E8ZR] (last updated Aug. 5, 2016).

36. Id.

37. Id.

38. Id.

39. Kelly Reinke, Syringe Exchange Program Distributed Throughout Marion County, CBS4 (Nov. 11, 2019), https://cbs4indy.com/2019/11/11/syringe-exchange-program-distributedthroughout-marion-county/ [https://perma.cc/TXQ8-AYXE]. 
were found to be directly related to intravenous drug use..$^{40}$

Stigmatizing the illness does not work; you cannot shame people sober. Criminalization does not work; imposing fines and jail time does not, largely, help substance use disorder sufferers gain access to quality long-term health care and treatment. What these traditional public policies and legal responses have done, mostly, is relegate these individuals to the shadows. There, they are dying. Alone. And, they are dying preventable deaths. It does not have to be this way, nor should it.

\section{B. Data on the Economic Impact}

For those unconvinced or unmoved by the human toll, the economic impacts associated with untreated substance use disorders, and particularly, with overdose deaths related to the disease, are incontrovertible. The national opioid epidemic has cost $\$ 2.5$ trillion in only four years. ${ }^{41}$ The Council of Economic Advisors to the President ("CEA") issued a staggering report detailing extensive economic costs being experienced across the country. ${ }^{42}$ In constructing its report, the CEA took into account the elevated health care costs, sacrificed contributions to the economy through stable employment, and elevated criminal justice costs due to the opioid drug problem. ${ }^{43}$

Such elevated costs are measurable, as shown by the Centers for Disease Control and Prevention's statistics. The lifetime cost of HIV treatment is estimated, at the 2010 inflation rate, to be $\$ 379,668$ per patient. ${ }^{44}$ Initially, hepatitis $\mathrm{C}$ treatment ranged from $\$ 84,000$ to $\$ 96,000$ per person in $2014 .{ }^{45}$ Since 2014 , the cost of hepatitis C-curing medication has fallen to roughly $\$ 40,000$ for Medicaid program recipients. ${ }^{46}$ Some private insurers have been able to negotiate even greater reductions in these drug prices. Treating those infected with hepatitis $\mathrm{C}$ can save an estimated $\$ 14.3$ billion in long-term health costs associated with the disease. However, the prohibitive cost of the medication means that treatment for all individuals currently hepatitis C-positive comes with a $\$ 69.5$ billion price tag. This has led insurance companies to restrict access to life-saving drugs and has been particularly challenging for Medicaid and other government programs

40. Id.

41. The Council of Econ. Advisors, The Full Cost of the Opioid Crisis: \$2.5 Trillion Over Four Years, White House (Oct. 28, 2019), https://www.whitehouse.gov/articles/full-cost-opioidcrisis-2-5-trillion-four-years/ [https://perma.cc/8JMV-6VC6].

42. The Council of Econ. Advisors, The Underestimated Cost of the Opioid Crisis, White House (Nov. 2017), https://www.whitehouse.gov/sites/whitehouse.gov/files/images/The $\% 20$ Underestimated $\% 20$ Cost $\% 20$ of $\% 20$ the $\% 20$ Opioid $\% 20$ Crisis.pdf [https://perma.cc/2XSS-WFRZ] [hereinafter Underestimated Cost].

43. Id.

44. Access to Clean Syringes, supra note 35.

45. Id.

46. Id. 
to fund. ${ }^{47}$

While the CEA agrees that the costs of substance use disorder's nonfatal consequences certainly negatively impact the economy, it estimates that the costs relating to premature deaths from drug overdoses are vastly more consequential and broadly under-accounted for. ${ }^{48}$ The CEA estimates these costs as the value of a statistical life ("VSL"), ${ }^{49}$ and it found that, in 2015 alone, opioid-involved overdose deaths accounted for an age-adjusted median cost of $\$ 431.7$ billion. ${ }^{50}$

To put this in perspective, the CEA's estimate for total costs related to the opioid epidemic, factoring in both nonfatal opioid misuse and accidental opioid overdose fatalities, cost $\$ 504$ billion - meaning the costs of opioid-related deaths far outnumbered those costs factored under the umbrella of nonfatal opioid misuse consequences. ${ }^{51}$ Again, this gives policymakers a clear, measurable, and collective goal: reduce accidental overdose deaths.

\section{Harm Reduction as a Primary Strategy}

While there is no single definition of harm reduction, the term refers to a collection of activities aimed at reducing harm and death among those with substance use disorder and is premised on values of public health and human rights. General tenets of the movement focus on (1) respecting the rights of people who use drugs; (2) relying on evidence-based public health solutions to address substance use disorder; (3) retaining a commitment to social justice by creating networks of resources for people who use drugs; and (4) avoiding stigma when addressing and working with individuals with substance use disorder. ${ }^{52}$

Harm reduction, as a drug policy strategy, is broadly underutilized compared to the more traditional mitigation efforts. In a 2018 survey conducted by The New York Times, thirty experts in the field - ranging from policymakers to drugtreatment specialists to public safety workers - were given a hypothetical in which they had $\$ 100$ billion over five years to spend on addressing the opioid epidemic. ${ }^{53}$ Of those experts, only four prioritized harm reduction strategies ahead of other strategies.$^{54}$ Despite this, the experts overall earmarked an average of $2 \%$ of their total funding dollars for a little-known subcategory within the harm reduction penumbra: safe consumption sites. ${ }^{55}$

47. $I d$

48. Underestimated Cost, supra note 42, at 2-3.

49. Id. at 3 .

50. Id. at 6 .

51. Id. at 8 .

52. What Is Harm Reduction?, HARM REDUCTION INT'L, https://www.hri.global/what-isharm-reduction [https://perma.cc/4KL8-3NAK] (last visited July 25, 2020).

53. Josh Katz, How a Police Chief, a Governor and a Sociologist Would Spend \$100 Billion to Solve the Opioid Crisis, N.Y. TIMES (Feb. 14, 2018), https://www.nytimes.com/interactive/ 2018/02/14/upshot/opioid-crisis-solutions.html [https://perma.cc/AA9W-2V9L].

54. $I d$.

55. Id. 


\section{SAFE CONSUMPTION SITES}

\section{A. The Basics}

Alternatively known under multiple monikers, including supervised consumption sites, safe-injection sites, safe-injection facilities, or community health engagement locations, a safe consumption site is a facility where individuals with substance use disorders can come to use safely, with medical staff at the ready to assist them if something goes wrong - such as an accidental overdose or unintentional fentanyl exposure. ${ }^{56}$ Facilities provide a space for individuals to bring already-purchased illicit drugs and use them with sterile equipment. Such facilities also often provide additional supplies and resources such as fentanyl-testing kits, take-home syringes to reduce shared needle use (akin to syringe exchange programs), and connecting individuals to needed social services and drug treatment referrals. ${ }^{57}$

Safe consumption sites have been widely utilized in Europe for decades ${ }^{58}$ and there are currently about 120 sites in ten countries worldwide. ${ }^{59}$ In that time, various measures have shown that safe consumption sites reduce the risk of disease transmission by providing sterile equipment that was properly disposed of after a single-use, encouraging safer use outside of the clinic, reversing thousands of drug overdoses, connecting individuals with needed clinical services like wound care or sexually transmitted infection screening, and providing access to social resources and drug treatment services. ${ }^{60}$

The fact that these sites had a measurable impact on the public health of the communities in which they opened can be seen by comparing before and after statistics. In the late $1990 \mathrm{~s}$, Canada was beginning to explore whether safe consumption sites, already in implementation in European countries, could help address substance use morbidities and mortalities in the country. The Vancouver Injection Drug User Study, implemented in 1996, attempted to examine substance use practices in the Vancouver area to get a snapshot of the public health impact. ${ }^{61}$ Their findings were instructive.

56. What Is an SCS?, YES TO SCS, https://www.yestoscs.org/whatisanses [https://perma.ce/ TPU6-24KJ] (last visited July 25, 2020).

57. Beau Kilmer et al., Considering Heroin-Assisted Treatment and Supervised Drug Consumption Sites In the United States 5 (2018).

58. Id.

59. Supervised Consumption Sites, Drug Pol'y Alliance, http://www.drugpolicy.org/ issues/supervised-consumption-services [https://perma.cc/Y36A-RWRJ] (last visited July 25, 2020).

60. Id. These specific observations were based on data from Insite, the Vancouver SCS that opened in 2003. Though, similar results have been reported in a host of other studies and articles from sites in Europe and Australia.

61. Evan Wood et al., Unsafe Injection Practices in a Cohort of Injection Drug Users in Vancouver: Could Safer Injecting Rooms Help?, 165 CANAdian MED. Ass'N J. 405, 406 (2001). 
Of 776 respondents, 214 or $27.6 \%$ reported sharing, borrowing, or lending needles within the previous six months. ${ }^{62}$ Although HIV-positive respondents were less likely overall to engage in shared needle use, more than $20 \%$ of them disturbingly still shared needles for lack of access to sterile injection equipment. ${ }^{63}$ Of the same respondents, $13.7 \%$ reported routinely injecting drugs in public. ${ }^{64}$ Startlingly, 581 respondents $-74.9 \%$ - reported injecting alone at least once. ${ }^{65}$ Intuitively, injecting illicit drugs alone is one of the most dangerous substance use practices because it all-but ensures death in the event of an overdose. All of these findings were in spite of Vancouver's implementation of a syringe exchange program, leading study authors to conclude that having a more substantial impact on these numbers would require "the establishment of supervised safer injecting rooms. ${ }^{{ }^{66}}$ These findings were published in $2001 .^{67}$

In 2003, Vancouver opened Canada's first safe consumption site, Insite. ${ }^{68}$ Early studies evaluating the efficacy of the Vancouver site delivered promising results. From December 2003 to June 2004, the Vancouver Injection Drug Users Study interviewed 431 injection drug users and found that only $11.4 \%$ reported using shared needles within the previous six months. ${ }^{69}$ Of the same population of respondents, those that used the new facility were $70 \%$ less likely to share needles. ${ }^{70}$ Another study found that HIV-positive individuals' likelihood of sharing needles had decreased from over $20 \%$ in a pre-Insite study to $16.5 \%$ in a post-Insite study. ${ }^{71}$ Additionally, the Vancouver community at large benefited from the safe injection practice education that more than one-third or $33.5 \%$ of Insite users received from May 2003 to October 2004. ${ }^{72}$ This additional public health resource, outside of the provision of strictly substance use services, illustrates the broad impact that safe consumption sites can have through community training, public health education, and referral resources.

These early evaluations appear to be standing up to the test of time. As of the end of 2018, Insite has had 3.6 million visits from individuals wishing to inject illicit drugs under supervision, 48,798 clinical treatment visits, and 6,440

62. Id.

63. Id. at 407.

64. Id.

65. Id.

66. Id. at 409 .

67. Id. at 405 .

68. Ian Bailey, The Inside Story of Vancouver's Safe Injection Site, GLOBE \& MAIL (Oct. 6, 2007), https://www.theglobeandmail.com/news/national/the-inside-story-of-vancouvers-safeinjection-site/article18146473/ [https://perma.cc/E9WM-R8R7].

69. Thomas Kerr et al., Safer Injection Facility Use and Syringe Sharing in Injection Drug Users, 366 LANCET 316, 316 (2005).

70. Id.

71. Evan Wood et al., Factors Associated with Syringe Sharing Among Users of a Medically Supervised Safer Injecting Facility, 1 AM. J. InfECTIOUs DiseAses 50, 52 (2005).

72. See Evan Wood et al., Safer Injecting Education for HIV Prevention Within a Medically Supervised Safer Injecting Facility, 16 InT'L J. DRUG POL'y 281, 282 (2005). 
overdose interventions without any deaths. ${ }^{73}$ In 2018 alone, there were 189,837 visits by 5,436 individuals. ${ }^{74}$ Also, there were 1,466 overdose interventions, 3,725 clinical treatment interventions such as wound care or pregnancy tests, and 443 client admissions to Onsite, the adjoining detox treatment facility where individuals had an average stay of 11 days. ${ }^{75}$

\section{B. Safe Consumption in the United States}

Currently, no sanctioned safe consumption sites exist in the United States, owing to the federal government's interpretation of the pejoratively-termed crack house statute of the Controlled Substances Act. ${ }^{76}$ This Code section prohibits the establishment of properties that will allow drug use on the premises of a house or building. ${ }^{77}$ Proponents argue that this legislation was aimed at combatting the establishment of drug houses, not medical facilities. ${ }^{78}$

An unsanctioned, underground safe consumption site has been operational in the United States in an undisclosed, urban area since $2014 .{ }^{79}$ The site is open five days per week for four to six hours per day and is accessible via invitation only. ${ }^{80}$ No more than sixty people are permitted to have carrying privileges, which is card-carrying access to the site, at any given time. ${ }^{81}$ Between 2014 and 2019, over 10,514 injections were carried out with only thirty-three overdoses, all of which were successfully reversed. ${ }^{82}$

Moreover, in a survey taken by each patient before injection, $67.4 \%$ of the visitors at this site self-reported that they had disposed of used syringes unsafely in the past thirty days. ${ }^{83}$ Because safe consumption sites dispose of all paraphernalia on-site, this facility alone prevented roughly 1,725 unsafe public

73. Insite User Statistics, VAncouver CoAstal Health, http://www.vch.ca/publichealth/harm-reduction/supervised-consumption-sites/insite-user-statistics [https://perma.cc/EJ96$8 \mathrm{~N} 2 \mathrm{M}]$ (last updated July 2019).

74. $I d$.

75. $I d$.

76. See Alex Kreit, Safe Injection Sites and the Federal "Crack House" Statute, 60 B.C. L. REV. 414 (2019).

77. 21 U.S.C. $\S 856(2020)$.

78. Nina Feldman, 'Crackhouse' or 'Safehouse'? U.S. Officials Try to Block Philly's Supervised Injection Site, KAISER HEALTH NEws (Sep. 9, 2019), https://khn.org/news/crackhouseor-safehouse-u-s-officials-try-to-block-phillys-supervised-injection-site/ [https://perma.cc/97SPMRM4].

79. Alex H. Kral \& Peter J. Davidson, Addressing the Nation's Opioid Epidemic: Lessons from an Unsanctioned Supervised Injection Site in the U.S., 56 AM. J. PREVENTATIVE Med. 919, 919 (2017).

80. Id. at 920 .

81. Id.

82. Alex H. Kral et al., Evaluation of an Unsanctioned Safe Consumption Site in the United States, 383 New Eng. J. Med. 589, 589 (2020).

83. Kral \& Davidson, supra note 79 , at 921. 
disposals of syringes or $67.4 \%$ of the 2,574 different injections over two years. ${ }^{84}$ In addition, the facility prevented over $90 \%$ of public injections, which would have otherwise occurred in a public bathroom or on a street, ${ }^{85}$ thus causing significant positive externalities for the public at large by preventing thousands of cases of public injections and potential police arrests.

While, at the time of this writing, no legally sanctioned safe consumption site has been opened in the United States, there is little doubt that they are coming. Officials from more than a dozen cities, counties, and states have started to actively study and discuss safe consumption sites as potential public health intervention tools in their jurisdictions. ${ }^{86}$

Seattle was the first city to approve plans to begin to lay the groundwork for the establishment of a safe consumption site in 2017. Legislation to enable the establishment of a site has been passed in San Francisco, Philadelphia, Ithaca, and New York City. ${ }^{87}$ Still, other legislative measures in additional states and counties have been introduced or are at least in the early stages and beginning to assign investigative committees to research the efficacy and feasibility of safe consumption sites. ${ }^{88}$

While Seattle was an early pioneer in the push to introduce sanctioned safe consumption sites, policymakers and public health officials quickly faced a wave of pushback as surrounding towns rapidly introduced legislation to ban the establishment of a site in their neighborhoods. A widely-circulated opposition petition gained nearly 50,000 signatures in the Seattle-metro area alone. ${ }^{89}$ The petition was dismissed by the courts, but the political controversy has forced proponents to compromise on a physical location by instead proposing a mobile site. ${ }^{90}$ Ongoing tension and pushback have significantly stalled the city's early gains and rapid progress. ${ }^{91}$ Instead, policymakers' and public health proponents' attention has increasingly turned to Philadelphia.

Safehouse, a Philadelphia nonprofit, moved forward with plans to open a brick and mortar site after city officials signaled their support. ${ }^{92}$ The federal Department of Justice vowed to fight any attempts to establish safe consumption sites in the United States ${ }^{93}$ and made good on that promise by suing Safehouse in

84. Id. at 920 .

85. Id.

86. Azeen Ghorayshi, The Feds Say Safe Injection Sites are Illegal. Here Are All the Places Considering Them Anyway., BuzzFeEd News (Sept. 6, 2018), https://www.buzzfeednews.com/ article/azeenghorayshi/safe-injection-site-proposals-map [https://perma.cc/8MR5-4HDH].

87. Id.

88. Id.

89. Id.

90. Id.

91. Id.

92. Office of the Mayor, Mayor Kenney Issues Statement on Overdose Prevention Sites, CiTY PHILA. (Apr. 18, 2019), https://www.phila.gov/2019-04-18-mayor-kenney-issues-statement-onoverdose-prevention-sites/ [https://perma.cc/LH67-N99A].

93. Rod J. Rosenstein, Fight Drug Abuse, Don't Subsidize It, N.Y. Times (Aug. 27, 2018), 
federal court last year. ${ }^{94}$ The government's civil suit sought declaratory judgment that the establishment of a safe consumption site would violate section 856 of the Controlled Substances Act. ${ }^{95}$

\section{Recent Developments}

In early October of last year, public health advocates and safe consumption site proponents won their first legal battle regarding the legality of the sites. A district court held that section 856 of the Controlled Substances Act did not apply to Safehouse's proposed site because the nonprofit's goal is "to reduce drug use, not facilitate it." Judge McHugh reiterated that the congressional intent in enacting section 856 was to outlaw drug houses, not medical treatment facilities. ${ }^{97}$

The legal battle to establish the first safe consumption site in the United States will continue, as the federal government has guaranteed it will appeal the decision in United States v. Safehouse ${ }^{98}$ and vigorously fight any other city's similar attempts to open a site. ${ }^{99}$ In a letter to Safehouse attorney Ilana Eisenstein, U.S. Attorney William McSwain cautioned that an opening of the site prior to exhaustion of the appeals process would, "force [his] hand, and [he would] have no choice but to take the steps necessary to maintain the status quo." 100 Listed among possible options included drug seizures, arrests for site users and staff, and criminal forfeiture proceedings. ${ }^{101}$

Similarly, pushback from residents of Kensington, the neighborhood marked for the establishment of Safehouse's first physical site, has galvanized opponents. ${ }^{102}$ After plans for the location of the site were revealed, legislation was introduced by some on the city council to change the zoning ordinance of the

https://www.nytimes.com/2018/08/27/opinion/opioids-heroin-injection-sites.html [https://perma.cc/PYG7-4BUK].

94. See United States v. Safehouse, 408 F. Supp. 3d 583 (E.D. Pa. 2019).

95. See Complaint for Declaratory Judgment, United States v. Safehouse, 408 F. Supp. 3d 583 (E.D. Pa. 2019) (No. 2:19-CV-00519), 2019 WL 462760.

96. Safehouse, 408 F. Supp. 3d at 618 .

97. Id. at 595 .

98. Id. at 618 .

99. Press Release, Jeffrey A. Rosen, Statement from Deputy Att'y Gen. Jeffrey A. Rosen on the United States v. Safehouse Ruling (Oct. 2, 2019), https://www.justice.gov/ opa/pr/statementdeputy-attorney-general-jeffrey-rosen-united-states-v-safehouse-ruling $\quad[\mathrm{https} / / /$ perma.cc/6CT7VX6F].

100. Jeremy Roebuck \& Aubrey Whelan, U.S. Attorney Threatens to Close Philly Supervised Injection Site If It Opens Before Appeals Courts Weigh In, PHILA. InQUIRER, https://www. inquirer.com/health/opioid-addiction/supervised-injection-site-philly-safehouse-appeal-mcswainmchugh-goldfein-20191015.html [https://perma.cc/5P3U-JTH5] (last updated Oct. 15, 2019).

101. Id.

102. Jake Blumgart, Kensington Neighbors Dismayed by Ruling on Supervised Injection Site, WHYY (Oct. 2, 2019), https://whyy.org/articles/kensington-neighbors-dismayed-by-ruling-onsupervised-injection-site/ [https://perma.cc/ZUK9-6CR8]. 
planned location from industrial-commercial to single-family residential to prevent a safe consumption site from being able to open there. ${ }^{103}$ Such moves illustrate the uphill nature of realizing the establishment of the first safe consumption site in the United States: community attitudes and perceptions towards people with substance use disorders, lack of education regarding evidence-based harm reduction, and fears regarding public health and safety.

However, the ruling in Philadelphia sets an important precedent for other cities looking for innovative and evidence-based harm reduction tools, like the creation of safe consumption sites, to combat drug-related morbidity and mortality in their communities.

As with almost every facet of our normal day-to-day existence, the emergence of the Covid-19 global public health crisis has impacted the national conversation and consciousness regarding safe consumption sites. In one vein, the pandemic has contributed to the stalling of the opening of Safehouse's safe consumption site. The same judge who found in Safehouse's favor at the trial court level granted the government's requested stay of these final orders, citing the upheaval related to the pandemic and ongoing social justice movement with regards to the killing of George Floyd by police. ${ }^{104}$ These issues, Judge McHugh wrote, "make this the wrong moment for another change in the status quo."105 Despite this move, Judge McHugh was abundantly explicit in his reasoning: that a stay was in the public interest, nearly exclusively, because of the unprecedented ongoing national tribulations. ${ }^{106}$ Specifically, Judge McHugh wrote that

[a]ll change results in some level of disruption, and Philadelphia has already experienced two profound disruptions. It is confronted with a public health crisis even larger than the opioid epidemic, which has strained municipal government and individual citizens to an unprecedented degree, imposing extreme demands on the City's resources and employees. At the same time revenues have dwindled because of the deep downturn in economic activity. The nerves of citizens are frayed by fear and uncertainty, and that was true before the death of Mr. Floyd and the widespread protests that arose in its aftermath.

The opening of Safehouse would require multiple public meetings, the time and attention of the City Health Department, and the allocation of police resources. Even if one assumes a flawless opening process, the operation of Safehouse would represent a significant change in how the City responds to opioid abuse, and such change would necessarily be

103. Id.

104. See United States v. Safehouse, No. 2:19-CV-00519, 2020 WL 3447775 (E.D. Pa June 24, 2020).

105. Id. at $* 1$.

106. Id. 
disruptive. $^{107}$

Despite this ultimate conclusion, Judge McHugh said that the government had not made any showing that (1) the opening of the site would frustrate any congressional purpose ${ }^{108}(2)$ the opening of the site would lead to riskier or increased drug use, ${ }^{109}$ (3) any tangible harm would be caused by opening the site without the full support of local and other government actors, ${ }^{110}$ or (4) the surrounding community would be harmed absent the stay. ${ }^{111}$

On the other hand, the ongoing Covid-19 crisis has led to a flurry of advocacy by public health professionals, medical experts, and attorneys who are gravely concerned about the enhanced negative impacts of the pandemic on the community of people living with substance use disorders. For this population, which already has suppressed access to health care, ongoing medication-assisted treatment and other services provided or referred by harm reduction programs are impacted by quarantining and social distancing requirements. ${ }^{12}$ Increasingly, people are touting the necessity of these sites to help the population with substance use disorders, especially during the pandemic. ${ }^{113}$ People with substance use disorders cannot quarantine without proper access to resources like medication-assisted treatment; in many instances, they cannot social distance. These facilities can support them through this time, and they can also better protect the community at large by providing Covid-19 screening and testing for site participants. ${ }^{114}$

As a result, California legislation allowing safe consumption sites is back for reconsideration, more than a year after it had been abandoned after passing but being vetoed by then-Governor Jerry Brown. ${ }^{115}$ Assembly Bill 362 would allow for the legal establishment of a safe consumption site in the San Francisco area. ${ }^{116}$ California legislators cite the pandemic for inspiring renewed focus on the issue. "During C[ovid]-19, the last thing we should be doing is shuffling people who use drugs into jails or waiting until an overdose sends them to the emergency

107. Id. at $* 13$.
108. Id. at $* 5$.
109. Id. at $* 6$.
110. Id. at *8.
111. Id.
112. Julian Mark, Colliding Epidemics: Need for 'Safe Consumption Sites' More Dire in
VID Era, Scientists and Lawmakers Say, Mission Loc. (July 20, 2020), https://missionlocal.org/ 2020/07/colliding-epidemics-need-for-safe-consumtion-sites-more-dire-in-covid-era-scientists-andlawmakers-say/ [https://perma.cc/LTB2-5XWG].

113. Jeffrey A. Singer, Safe Injection Sites: Coronavirus Underlines Why They Make Sense, CAto Inst. (Mar. 17, 2020), https:/www.cato.org/publications/commentary/safe-injection-sitescoronavirus-underlines-why-they-make-sense [https://perma.cc/2TDQ-UPGB].

114. Id.

115. Mark, supra note 112.

116. Id. 
room," one lawmaker said. ${ }^{117}$

This promising turn is further emphasized by a recent amicus brief, signed by nine Attorneys General across the country, supporting the Safehouse site in Philadelphia. ${ }^{118}$ This brief stresses the traditional state role as the arbiter of public health and safety, and it emphasizes a state's right to respond to its unique public health challenges with "cutting-edge medical interventions." 119 It also calls into question the federal government's interpretation of section 856 of the Controlled Substances Act, saying it invokes a constitutional question regarding states' police powers - among which is the right of the state to regulate the practice of medicine within its borders. ${ }^{120}$

As California lawmakers and State Attorneys General across the nation show us, and precisely because of the novel nature of the ongoing challenges the pandemic and other national issues have presented us with, the time is ripe for indepth study and policy work on how safe consumption sites can be implemented in jurisdictions across the country. Indiana must have a place in the emerging national discourse regarding harm reduction through safe consumption sites.

\section{THE PATH FORWARD FOR A SAFE CONSUMPTION SITE IN INDIANA}

Indiana gained national and global notoriety in the worst way possible as the State became a case study on how not to react to a public health crisis. ${ }^{121}$ The outbreak of HIV and hepatitis C in rural Scott County, driven by shared use of needles for intravenous drug use, was a devastating portrait of what can happen when policymakers turn a blind eye to evidence-based science. ${ }^{122}$ For decades, Indiana lawmakers had been staunchly opposed to syringe exchange programs, initiatives that were long-proven to be effective at reducing disease transmission related to intravenous drug use by providing people with substance use disorders with clean syringes. ${ }^{123}$

A historically conservative state, Indiana made the establishment of syringe exchange programs illegal under state law. ${ }^{124}$ The Scott County epidemic

117. Id.

118. See Brief for D.C. et al. as Amici Curiae in Support of Brief for Appellee Safehouse \& Affirmance, United States. v. Safehouse, No. 20-1422 (3d Cir. July 6, 2020).

119. Id.

120. Id.

121. Heather Boerner, Mapping How the Opioid Epidemic Sparked an HIV Outbreak, WFYI INDIANAPOLIS (Jan. 14, 2018), https://www.npr.org/sections/health-shots/2018/01/14/577713525/ mapping-how-the-opioid-epidemic-sparked-an-hiv-outbreak [https://perma.cc/9GDT-QAQV].

122. Issie Lapowsky, Indiana, Reeling from Opioid Crisis, Arms Officials with Data, WIRED (Sept. 14, 2017), https://www.wired.com/story/indiana-reeling-from-opioid-crisis-arms-officialswith-data/ [https://perma.cc/DE9M-W6VH].

123. Austin Frakt, Politics Are Tricky but Science Is Clear: Needle Exchanges Work, N.Y. TiMEs (Sept. 5, 2016), https://www.nytimes.com/2016/09/05/upshot/politics-are-tricky-but-scienceis-clear-needle-exchanges-work.html [https://perma.cc/3SSQ-2BXF].

124. Nicholas Golding, The Needle and the Damage Done, 14 Ind. Health L. Rev. 173, 189 
ultimately led ultra-conservative, then-governor Mike Pence to lift the state ban on exchange programs, but not until a few hundred cases had cropped up in the small community. ${ }^{125}$ Many Hoosiers still hold Pence's and other Indiana lawmakers' feet-dragging, with regard to allowing syringe exchange programs in Indiana, accountable for a preventable outbreak.

In the years since, a majority of Indiana lawmakers have been increasingly receptive to the public health and evidence-based science regarding syringe exchange programs, and they have passed legislation to allow for increased access to such programs. ${ }^{126}$ In 2017, the republican-held State Senate voted 32-16 to expand syringe exchange programs by allowing local governments to initiate their own programs without state authorization and removing the requirement that the State Health Commissioner declare a public health emergency before a syringe exchange program could be established. ${ }^{127}$ The bill was then signed into law by Governor Eric Holcomb. ${ }^{128}$ Since that time, several counties, including Marion County, have successfully piloted syringe exchange programs. ${ }^{129}$ This shift is an excellent first step in the use of harm reduction strategies. The next step is to contemplate a path forward for the establishment of a pilot safe consumption site.

\section{A. The Indiana Code}

Despite the progressive, evidence-based changes Indiana lawmakers have made in recent years with regards to public health and the fight to mitigate the effects of substance use disorder in Indiana, installation of a safe consumption site will still require an overhaul of Indiana drug law, tweaks to local law for those jurisdictions pursuing the installation of a site, and a well-designed and clearly articulated advocacy strategy to build a coalition of support between policymakers, public health and safety professionals, and residents.

(2015).

125. Paul Demko, How Pence's Slow Walk on Needle Exchange Helped Propel Indiana's Health Crisis, Politico (Aug. 7, 2016), https://www.politico.com/story/2016/08/under-pencesleadership-response-to-heroin-epidemic-criticized-as-ineffective-226759 [https://perma.cc/PF9XFWCN].

126. Brandon Smith, House Approves Syringe Exchange Bill, Sends It to Senate, WFYI INDIANAPOLIS (Jan. 31, 2017), https://www.wfyi.org/news/articles/house-approves-syringeexchange-bill-sends-it-to-senate [https://perma.cc/YYV5-9A3C].

127. H.B. 1438, 120th Gen. Assemb., 1st Reg. Sess. (Ind. 2017).

128. Associated Press, Indiana Gov. Holcomb Signs Pre-K Expansion, Needle Exchange Bills, CHI. TRIB. (Apr. 26, 2017), https://www.chicagotribune.com/suburbs/post-tribune/ct-indianaholcomb-signs-bills-20170426-story.html [https://perma.cc/T9K6-T52L].

129. Syringe Service Program Providing Counties, IN.gOv (July 18, 2018), https://www.in. gov/isdh/files/SSP\%20Map\%20-\%20July\%202018-EC.pdf [https://perma.cc/SL3Q-WB37] (showing that Madison and Lawrence counties enacted SEPs, but have since terminated or failed to renew them). 


\section{Indiana Drug Laws}

Indiana drug law outlines a 5-Schedule scheme in which controlled substances are categorized based on their potential for abuse balanced against their potential medicinal benefit. ${ }^{130}$ Drugs with the highest potential for abuse and the lowest recognized benefit are determined to be Schedule I drugs and carry the highest associated penalties for possession, distribution, and more. ${ }^{131}$ Schedule V drugs, inversely, are judged to have a low likelihood of abuse and invoke lesser penalties. ${ }^{132}$ Possession of any substances classified in Schedules I through IV without a valid prescription is criminalized and can incur a Class A misdemeanor in Indiana. ${ }^{133}$ Additionally, penalties apply if there is an enhancing circumstance that can elevate the charge to a Level 6 felony. ${ }^{134}$ Moreover, heightened penalties apply to possession of either cocaine or a narcotic. ${ }^{135}$ This presents a problem for the establishment of safe consumption sites.

The premise of the sites is that all materials for supervised use would be provided - including syringes, stoppers, sterile gauze, alcohol pads, tourniquets, and bandages. These are all materials except for the controlled substances themselves, which would be provided by the site users. Therefore, these users must necessarily possess the controlled substances in transit to the site. Most drugs used at the site would likely be either cocaine or a narcotic, such as heroin, and, therefore, subject to more stringent drug prosecution. At the very least, those found in possession of either substance could immediately be charged with a Level 6 felony, with increasing severity as the amount possessed increases. ${ }^{136}$ This criminalization would make access to the site incredibly difficult and risky for individuals because the mere transit to the site would be classified as a criminal endeavor.

Administrators of Indiana's syringe exchange program faced a similar dilemma. Though the program was allowed to be initiated, even expanded possession of a syringe was - and still is - a Level 6 felony in Indiana. ${ }^{137}$ For site users, this made traveling to and visiting the site, where they were expected to return with used needles in exchange for sterile ones, incredibly risky. If site users were stopped and searched by police, they were subject to the State's possession penalties, regardless of the fact that they were attempting to engage in a lawful public health outreach program. This has made individuals with substance use disorder extremely wary of engaging with the sites and has dampened the positive effects and wide reach the programs could have but for the continued

130. Drug Schedules 1-5, IN.GOV, https://www.in.gov/isdh/27380.htm [https://perma.cc/49GHD2ZL] (last visited Oct. 18, 2020).

131. Id.

132. $I d$.

133. IND. CODE $\S 35-48-4-7$ (2020).

134. IND. CODE $\S 35-48-1-16.5$ (2020).

135. IND. CODE $\S 35-48-4-6(2020)$.

136. Id.

137. IND. CODE $§ 16-42-19-18$ (2020). 
criminalization of syringe possession.

To attempt to reconcile this contradiction, some Indiana counties have opted for an identification card of sorts. ${ }^{138}$ Essentially, the cards have an identification number that cannot be used to personally identify a program participant, as that violates state law, ${ }^{139}$ but can verify that the individual is a program participant. ${ }^{140}$ Law enforcement officers are encouraged to use their own discretion and may still initiate arrests for syringe possession, but possession of the card, ideally, may encourage the officer to show leniency. ${ }^{141}$ Additionally, many of the cards have the posted hours of operation for when the local syringe exchange program is accessible, helping an officer further discern the context of possession and determine whether the individual is in transit to the facility or is merely in possession of a syringe for purposes unrelated to the use of a public health program. ${ }^{142}$

While the ideal solution and goal would be to decriminalize possession of a syringe to allow individuals with substance use disorders unfettered access to harm reduction programs, a feasible first step is to implement broad card-carrying provisions that are recognized across county lines. This way, those actively seeking cleaner, safer instruments can come out of the shadows, use safely, and have fewer morbidities associated with intravenous drug use. These concepts can and must be applied to safe consumption sites too if they are to be successful.

While site visitors coming to a safe consumption site may be less concerned with the State's laws governing possession of syringes and other paraphernalia because these materials would be lawfully provided by the site administrators, the criminal consequences for possession of a controlled substance is a big hurdle. It carries the potential for significant criminal penalties and directly burdens access to the harm reduction resources offered by the sites. Similar to some of the solutions proposed by the syringe exchange administrators, safe consumption site advocates could propose that site visitors be provided with non-identifying, participation cards that they could carry to provide an officer in the event of a stop and search.

These cards would identify them as users of the site and, as such, participants in the lawful public health harm reduction program. Additionally, the absence of

138. Ja'Nel Johnson, How the Scott County, Indiana, Needle Exchange Program Works, 89.3 WFPL (Apr. 22, 2015), https://wfpl.org/scott-county-indiana-needle-exchange-program-works/ [https://perma.cc/U7R8-443Z].

139. Ind. State Dep't of Health, Indiana State Department of Health Syringe Services \& Harm Reduction Program Manual for Local Health Departments Version 3.0, IN.GOV 19 (Sept. 2017), https://www.in.gov/isdh/files/Guidance\%20Document\%20-\%202017\%20Update\%20-\%209-12-17EC.pdf [https://perma.cc/V57J-JPN3].

140. Johnson, supra note 138.

141. Aprile Rickert, With a Needle Exchange, How Do Clark County Officials Enforce Syringe Laws?, News \& TRIB. (Aug. 14, 2017), https://www.newsandtribune.com/news/with-a-needleexchange-how-do-clark-county-officials-enforce/article_307bd15c-7f90-11e 7-8785bf5213a653ab.html [https://perma.cc/EV3H-4JYL].

142. IND. CODE $\S 35-48-1-16.5$ (2020). 
additional paraphernalia could indicate the individual's intent to use at the site, under medical supervision and with the site's sterile equipment. Additional context, such as prominently listed site locations and hours, could further help an officer discern the context of the possession.

\section{Indiana Public Health Laws}

Additionally, an enabling statute along the lines of Indiana's Syringe Exchange Program Law, ${ }^{143}$ as Amended per House Enrolled Act $1438,{ }^{144}$ would likely be necessary to empower municipalities to begin even the earliest planning stages for a pilot safe consumption site. Many provisions of the law are sound and could likely be, quite literally, copied and pasted into an Indiana Safe Consumption Site Law. For example, section 6's duties for the syringe exchange program could easily be transcribed into a safe consumption site enabling statute. These duties include, inter alia, provisions that the sites be registered with both the state and local health departments, have program administration overseen by a licensed medical professional, properly dispose of syringes and other paraphernalia, and that no personally identifiable information be collected or recorded at the site. ${ }^{145}$

However, there are several areas of concern to think through before the drafting of an enabling statute for safe consumption sites begins. To start, even as recently amended to allow more flexibility and autonomy at the local level, the enabling statute, with regards to syringe exchange programs, still remains too rigid of a framework for safe consumption sites to operate successfully within. As such, there would need to be key differences in the drafting of the two laws.

For example, the law allows syringe exchange programs to remain in effect for up to two years, and then, either be renewed for another two-year period or be terminated. ${ }^{146}$ This two-year timeline is too accelerated for adequate creation, installation, and administration of a site with time allowed to begin to evaluate the program's efficacy.

Madison Weintraut, the current program manager for Marion County's Syringe Access Program, emphasized the grueling timeline she had to work with to get Marion County's first syringe program off the ground. First came the extensive and protracted grassroots campaign to get local lawmakers and community stakeholders on board with creating the program. Then came a strenuous lobbying effort to get authorizing legislation passed. Once passed, she and her team had to identify funding since, by law, no state or federal funds may be used for the purchase of syringes. ${ }^{147}$ After that, they had to (1) designate a site - a difficult task, (2) create and stock mobile units, (3) staff and deploy units in the community, (4) gain the trust of the substance use disorder community to get

143. IND. CODE $§ 16-41-7.5$ (2020).

144. H.B. 1438, 120th Gen. Assemb., 1st Reg. Sess. (Ind. 2017).

145. IND. CODE $\S 16-41-7.5-6$ (2020).

146. See Ind. CodE $\S 16-41-7.5-11$ (2020).

147. Ind. State Dep't of Health, supra note 139. 
them to engage with the program, and finally (5) wholly administer the program. After all of that, she then had to attempt to collect program data and evaluate the early results of the program. ${ }^{148}$

Thus, while all the practical steps of designing, implementing, administering, and evaluating the program are ongoing, vigorous lobbying for renewal has to be taking place simultaneously. This is a nearly impossible framework within which syringe exchange programs must work. The logistical demands of establishing a safe consumption site, coupled with their novelty and politically controversial nature, mean a two-year renewal provision would almost certainly doom a pilot site.

I propose that no renewal period be added to an enabling statute, but rather that the language allows for termination of a program at the evidence-based discretion of the local public health authority in the municipality in which it operates. For example, Dr. Virginia Caine, Director of the Marion County Public Health Department, would be allowed to determine renewals in Marion County based on the data compiled by a harm reduction task force or other committee charged with collecting and evaluating the efficacy of the sites and general overdose or disease transmission rates in Marion County.

Indiana lawmakers could also look to the roadmap drawn by the proposed local ordinance for a safe consumption site ( "Overdose Prevention Program") out of California. ${ }^{149}$ This ordinance develops oversight authority and regulatory enforcement power, placing it in the hands of the Department of Health, ${ }^{150}$ as recommended above. Additionally, it outlines a permit process, creates operating standards, provides for inspections, imposes reporting requirements, and enumerates permit revocation processes and other penalties for noncompliance. ${ }^{151}$ Finally, the ordinance affirmatively calls for law enforcement to "deprioritize enforcement of laws prohibiting possession of illegal drugs and drug paraphernalia against those individuals . . . access[ing] an Overdose Prevention Program," allowing for these individuals to more freely access the public health resource without fear of immediate criminalization. ${ }^{152}$

Allowing for local policymakers and public health officials to narrowly study substance use in their communities, and providing them with the autonomy to enact, expand, reduce, or terminate programs based on their knowledgeable assessment of the need, makes for better and more receptive policymaking at the local level. It also alleviates the political pressures safe consumption site administrators have to face. This way, they can more squarely focus on administering a desperately needed public health service.

148. Madison Weintraut, Program Manager, Marion Cty. Syringe Access Program, Presentation to the Indiana University Robert H. McKinney School of Law Opioid Litigation Seminar Class (Aug. 5, 2019) (notes on file with the author).

149. S.F., Cal., Ordinance 105-20 (Aug. 10, 2020).

150. $I d$.

151. Id.

152. Id. 


\section{B. Local Law and the Hurdle of Home Rule}

Opponents of safe consumption sites have a wealth of tools at their disposal to block the establishment of a site. One universal favorite is to use preemptory zoning legislation to prevent physical sites from being established. Such are colloquially known as not-in-my-back-yard ("NIMBY") laws.

After the location of the planned Safehouse site in Philadelphia became public, a city-county councilman introduced legislation - which passed - to convert the proposed space from industrial-commercial to single-family residential. This effectively prevented Safehouse from being able to open at that site. ${ }^{153}$ For good measure, the city-county council approved the lease of the site to another entity the day before the Safehouse decision came down. ${ }^{154}$

To further assail the possibility that Safehouse will be able to open its planned safe consumption site, a state senator proposed legislation to preempt localities from being able to open safe consumption sites. ${ }^{155}$ This is a common exercise across the country in a variety of matters, even those outside the scope of public health law, when more conservative state governments are confronted with more progressive municipalities.

Indiana exemplifies this tension perfectly. Popularly termed home rule acts are supposed to grant local leaders greater flexibility, enable increased responsiveness, and foster innovative policymaking for unique challenges. ${ }^{156}$ Indiana's Home Rule Act of 1980, oxymoronically, enumerates a long list of restrictions. ${ }^{157}$ State lawmakers have used it to prevent local lawmakers from setting local minimum wages, regulating housing, regulating worker schedules, and implementing environmental initiatives - like outlawing plastic bags, as other municipalities have done. ${ }^{158}$ There is also a significant trend in the passing of aggressive state preemption laws when localities attempt to institute innovative public health laws. ${ }^{159}$ It is conceivable that a similar move to preempt the establishment of a pilot safe consumption site in Indiana would be introduced and likely passed.

153. Blumgart, supra note 102.

154. Id.

155. Elizabeth Hardison, Williams Says Supervised Injection Sites Aren't the Answer to Fighting Drug Use. So He Wants to Ban Them, PHILA. TRIB. (Oct. 3, 2019), https://www.phillytrib. $\mathrm{com} /$ news/local_news/williams-says-supervised-injection-sites-aren-t-the-answerto/article_c282e1a6-7b64-5b11-9a01-067e74e0c46f.html [https://perma.cc/Z3EZ-BWJW].

156. Samuel B. Stone, Home Rule in the Midwest, Ind. UnIV. Pub. PoL'Y Inst. 1 (July 2010), http://ppidb.iu.edu/Uploads/PublicationFiles/PC_HmRules_Web.pdf [https://perma.cc/G6CZC2TZ].

157. Joshua Claybourn, In Defense of Hoosier Home Rule, IndyStaR (May 7, 2017), https://www.indystar.com/story/opinion/2017/05/07/claybourn-defense-hoosier-homerule/101289696/ [https://perma.cc/8UA8-ENLT].

158. $I d$.

159. See Lori Riverstone-Newell, The Rise of State Preemption Laws in Response to Local Policy Innovation, 47 Publius 403 (2017). 
The Indiana Legislature's aggressive use of preemptive action, coupled with the overwhelmingly conservative make-up of this legislative body, make it all but certain that any locality planning a pilot safe consumption site would be quickly prevented from doing so. Only two solutions to this reality exist: (1) a coordinated and prolonged campaign to decentralize the power of the State Legislature and disperse more power back to local communities; ${ }^{160}$ or (2) convince the State Legislature that a pilot site is essential for the public health of Indiana residents through a robust advocacy and education campaign. Though an idealistic notion, it is not completely outside of the realm of possibility. It is exactly what advocates did to get syringe exchange programs greenlighted just a few short years ago.

Moreover, Indiana lawmakers have little to lose by enabling a pilot safe consumption site. Such sites, as proposed here, would take no funding from state or local governments, but would instead have licensed nonprofits and private health care providers administer the sites at the direction of the local public health authority. Similar structures have been proposed in Utah, ${ }^{161}$ Denver, ${ }^{162}$ and San Francisco. ${ }^{163}$ Most early legislation from these policymakers also imposes reporting requirements, strict oversight from the applicable public health authority, and mandatory regulation of facility administrators in terms of individual licensure, in-facility training, and delivery of treatment resources to site users. ${ }^{164}$ Implementing similar measures in the design of a proposed pilot in Indiana could help assure lawmakers of their oversight authority while abstaining from diverting public funds to the program - a more politically palatable compromise for more conservative legislators.

\section{Other Novel Legal Issues}

Outside of the legal questions posed in pending litigation, a whole host of other novel legal issues surrounding safe consumption sites are likely to arise. Related to the previously mentioned zoning and NIMBY fights, some attorneys caution due process claims are likely to crop up. ${ }^{165}$ The Safehouse litigation has

160. Claybourn, supra note 157.

161. Nate Emery, Safe Injection Sites Will Save Lives, If Legislators Let Them, DAILY UTAH Chron. (Mar. 7, 2020), https://dailyutahchronicle.com/2020/03/07/emery-safe-injection-sites/ [https://perma.cc/75EK-57VX].

162. Anusha Roy \& Jacob Rodriguez, How Safe Injections Sites Would Work in Denver, 9NEws (Nov. 28, 2018), https://www.9news.com/article/news/local/next/how-safe-injections-siteswould-work-in-denver/73-618624287 [https://perma.cc/46BU-8CHG].

163. Jay Barmann, Mayor Breed Pushes Again for Safe Injection Sites, SFIST (Feb. 28, 2020), https://sfist.com/2020/02/28/mayor-breed-pushes-again-for-safe-injection/ [https://perma.cc/Q52DYHST].

164. Id.

165. Max Mitchell, Novel Legal Fights Loom as the Nation's First Safe Consumption Site Gains Court Approval, Legal InTELligencer (Feb. 26, 2020), https://www.law.com/ thelegalintelligencer/2020/02/26/novel-legal-fights-loom-as-nations-first-safe-injection-site-gains- 
already stirred up such a claim in Philadelphia, with one local attorney claiming he has been approached with a claim from residents alleging that their home property values were being taken without due process because of the way the proposed location for the Safehouse site had been determined. ${ }^{166}$ Also, they maintain that they were not afforded a proper public hearing. ${ }^{167}$ Since plans for this particular site have stalled, the issue is currently moot. However, it will assuredly rise again once a new location has been determined, providing a case of first impression for the courts.

Still, other challenges are plausible. Additional zoning challenges, one real estate litigator anticipates, will center around permitted use disputes. ${ }^{168}$ Zoning litigation commonly centers around common health care facility permits and definitions of things such as hospitals or residential recovery centers, but the precise definition and application of permitted use regulations for facilities like safe consumption sites will create a completely new regulatory scheme. ${ }^{169}$

Professional licensing could also see some safe consumption site-related litigation. Brian Quinn, a Philadelphia lawyer practicing in this area, specifically calls out the potential issues facing practicing health care professionals and their obligatory reporting requirements: would these workers be duty-bound to report seeing a fellow colleague visiting the site as a patient? ${ }^{170}$ Would patient confidentiality bar them from such action? Questions abound.

Anticipating the diverse and complex legal landscape in which the first safe consumption site would have to navigate is key to forming a comprehensive and successful implementation strategy and advocacy campaign.

\section{Advocacy and Implementation Strategy}

Assuming that a legal landscape for a safe consumption site pilot can be carved out, the next steps to realizing the actual implementation of a site will require innovative funding strategies, an aggressive public education campaign, and a supremely well-coordinated advocacy campaign.

One of the biggest hurdles, aside from legal challenges, is how to fund and sustain a site once it has been greenlighted. Safehouse operators in Philadelphia, despite winning their initial court battle over the legality of their planned site and their own vows to open the site as appeals are ongoing, have had to stall opening partly for lack of funding. ${ }^{171}$ Certainly, there would be no federal or state funding

\footnotetext{
court-approval/ [https://perma.cc/8TXF-V6UG].

166. Id.

167. Id.

168. Id.

169. Id.

170. Id.

171. Max Marin \& Nina Feldman, Supervised Injection at Prevention Point? Ahead of Major Ruling, Safehouse Lacks Location and Funding, BiLly PENN (Jan. 16, 2020), https://billypenn.com/ 2020/01/16/supervised-injection-at-prevention-point-ahead-of-major-ruling-safehouse-lackslocation-and-funding/ [https://perma.cc/VSJ7-VCVS].
} 
available for such an endeavor, especially at the outset - federal and state funds still cannot be used to procure syringes for syringe exchange programs. Thus, financial support will have to originate elsewhere.

One potential model would be a partnership with an existing institution to secure affordable space or financial support. Churches and other public health and welfare nonprofits would be ideal. In Marion County, a particularly involved eastside church, the Brookside Community Church, has been incredibly vocal in its support of harm reduction strategies and has partnered with the Marion County Health Department to serve as a host site for its current Syringe Access Program. ${ }^{172}$

As safe consumption sites increase in visibility and continue to become a more normalized feature of drug policy rhetoric, likely more prominent partners could be identified. In an ideal world, local hospitals and clinics that have existing relationships with vulnerable populations and communities of persons experiencing substance use disorders could house and administer physical safe consumption facilities. Indianapolis's Eskenazi Health stands out as a potential pilot operator, given its status as the public hospital for our county, its position under the Health and Hospital Corporation umbrella, and close working relationship with the Marion County Public Health Department. Such a partnership would provide space, funding, and trained medical staff to support and sustain safe consumption operations over the long-term. It would also serve to normalize the sites as places providing essential health care services. This could help destigmatize the use of such facilities.

Another critically important feature of this implementation strategy is the creation of a targeted public education campaign. A study found that only $29 \%$ of people support the legalization of safe consumption sites. ${ }^{173}$ While this is a dismaying statistic, it is important to view it through a contextual lens. For example, syringe exchange programs, now widely implemented, enjoy only a $39 \%$ public approval rating. ${ }^{174}$ So, while advocates will want to help craft a public health education campaign with regards to the efficacy of safe consumption sites as harm reduction mechanisms, high public support is not determinative of implementation, generally.

Where public support is critical with regards to the sites is when and where site locations are formally proposed. Cities attempting to earmark locations for sites to be erected have, pretty resoundingly, been met with fierce resident opposition. Empirically, residents do not want safe consumption sites in their backyards. This is despite the evidence that safe consumption sites generally reduce overdoses in the vicinity surrounding their location, as compared to other

172. David Cederquist, Why Brookside Partnered with Safe Syringe Exchange Program, BRookside CTy. Church (Apr. 17, 2019), https://www.bccindy.org/journey/why-safe-syringeexchange [https://perma.cc/Z4J6-8RK4].

173. Emma McGinty et al., Public Support for Safe Consumption Sites and Syringe Services Programs to Combat the Opioid Epidemic, 111 Preventative Med. 73, 73 (2018).

174. Id. 
neighborhoods in the same city. ${ }^{175}$ While many factors can produce the effect of lowered drug overdoses, one recent study "demonstrate[d] that Vancouver's supervised injection facility appears to have had a localized yet significant effect on overdose mortality in the area of densely concentrated injection drug use where the facility is located." 176

Opposition to locations proposed for a Philly-based safe consumption site has contributed to the stalled Safehouse plans in the wake of the nonprofit's October 2019 trial court victory. Despite assurances that Safehouse would charge forth in opening the inaugural site during the appeals process, the group has faced staunch pushback from residents and neighborhood groups. This opposition movement spurned the proposal of a state bill designed to outlaw the sites altogether. ${ }^{177}$ Support for the bill to criminalize the site garnered bipartisan support, owing to politicians' frustration at the lack of community involvement in Safehouse's planning and implementation process. ${ }^{178}$

To be sure, Safehouse's advocacy strategy notably and mistakenly lacked community input on the location of the proposed site. ${ }^{179}$ This shortcoming has continued to deeply divide the community. Rather than attempt to reach out to concerned neighborhood groups and opposition advocates, Safehouse has leaned on medical professionals, public health experts, and academics to try to scientifically refute community concerns. ${ }^{180}$ This strategy has forged a deep divide between what many South Philly residents view as an us vs. them dichotomy, with liberal-leaning academic elites pushing their harm reduction strategy on non-consenting residents. ${ }^{181}$ This tension was highlighted in a recent city council meeting on the matter, held March 16, 2020, where residents and public health officials verbally clashed. ${ }^{182}$ The path taken by Safehouse and its

175. See Brandon Marshal et al., Reduction in Overdose Mortality After the Opening of North America's First Medically Supervised Safer Injection Facility: A Retrospective Population-Based Study, 377 LANCET 1429 (2011).

176. Brandon Marshal et al., Critique of Lancet Study of Vancouver's Supervised Injection Site and Overdose: Authors' Response, B.C. CTR. FOR EXCELLENCE IN HIV/AIDS 5 (2011), http://www. cfenet.ubc.ca/sites/default/files/uploads/lancet-response.pdf [https://perma.cc/P6BV-QAL5].

177. Anna Orso, Supervised Injection Site Debate Revives Bill that Would Explicitly Criminalize Them, Philly Politicians Say, PhILA. INQuiRer (Mar. 2, 2020), https://www.inquirer.com/news/ supervised-injection-site-senate-bill-anthony-williams-kenyatta-johnson-20200302.html [https://perma.cc/2855-9ZQH].

178. Id.

179. Allison Steel \& Justine McDaniel, 'Disrespected': How South Philly Mobilized Against the Proposed Supervised Injection Site, PHILA. InQuiRer (Feb. 28, 2020), https://www.inquirer. $\mathrm{com} /$ news/supervised-injection-site-safehouse-south-philadelphia-protest-20200228.html\#loaded [https://perma.cc/5K3Z-3QWJ].

180. Id.

181. Id.

182. Tom Beck, The Safe Injection Site Fight is Shaping Up to Be a Battle Between Residents and Health Experts, S. PHILly REV. (Mar. 17, 2020), https://southphillyreview.com/2020/03/17/ the-safe-injection-site-fight-is-shaping-up-to-be-a-battle-between-residents-and-health-experts/ 
advocates, by neglecting to foster open community dialogues regarding the sites, may have stunted progress on any establishment of a site in South Philly in the near future, despite early legal success.

Future advocacy strategies must focus on building community buy-in, especially for the tough question: where to establish the sites. With a well-crafted, thoughtful, and culturally competent public education campaign designed to present the evidence-based benefits of safe consumption sites in a way that allows communities to collectively share ideas and concerns regarding the project, public health professionals, local lawmakers, and neighborhood groups can build support for these health care facilities.

No community is untouched by substance use disorder, and increasingly, few individuals are either. Communities are hungry for practical and efficacious solutions to the challenges presented by substance use disorder. Public health advocates and policymakers can deliver on this need while simultaneously building trust and social infrastructure in the targeted community.

\section{CONCLUSION}

Dr. Jonathan Giftos, Clinical Director of Substance Use Treatment for the New York City Health and Hospitals Corporation, stated it best in a Tweet, saying, "[n]o one is arguing that [supervised consumption sites] are THE answer to our overdose crisis, but they would fill an enormous gap in [the] current care model - engaging a highly marginalized group of patients - and ultimately sav[ing] many lives." 183

While the solution proposed here to help bring a safe consumption pilot site to Indiana would not constitute a one-stop solution to the broad problem of substance use disorder and its associated morbidities and mortalities in the State, it would be the first stop on a long journey toward destigmatizing and decriminalizing substance use disorder, recognizing illicit drug use as a symptom of an underlying disease, and providing resources for individuals to have a better chance mitigating recurrence of the symptoms and long-term recovery from the disease.

Safe consumption sites, until very recently, were either unknown or unfairly deemed radical fringe policy proposals in the United States. Now, they are gaining recognition and acceptance as real harm reduction mechanisms in public health professional and policymaking circles.

Even more encouraging is the emerging national consciousness regarding safe consumption sites. Even a few years ago, relatively few people outside the public health world were aware of what safe consumption sites were or that such facilities existed at all. Yet, this once-obscure public health concept is now being discussed in mainstream pop culture. A prime-time medical drama, Chicago Med, recently introduced a major plotline revolving around a main character's

[https://perma.cc/4NWU-MSR6].

183. Jonathan Giftos (@JonGiftosMD), Twitter (Aug. 28, 2018, 8:39 AM), https://twitter.com/JonGiftosMD/status/1034420183446773760 [https://perma.cc/AK77-CZXM]. 
campaign to implement a safe consumption site run by the hospital.

While health policy is certainly not set by fictional television plotlines, the mere fact that a major network would greenlight the storyline at all means that safe consumption sites are moving from the periphery to the mainstream of rhetoric and policy discourse. Additionally, culture often shifts the political and social climate and can thrust fringe issues into the national spotlight. Given that a January 2020 episode of Chicago Med was viewed by a whopping 8.37 million viewers, ${ }^{184}$ and Chicago Med's routine position as a top-watched Wednesday night network show week-to-week, ${ }^{185}$ its place in pop culture discourse is notable.

As a main character delivered an impassioned monologue about how safe consumption sites could have prevented the overdose death of his beloved brother, I wondered how many casual entertainment consumers were painfully reminded of their own loved ones. Doubtless, more than a few of those 8.37 million viewers have a family member or friend or are themselves struggling with a substance use disorder.

Certainly, I thought of Dave and how differently his story would have read had he had access to one of these life-saving facilities. Would he have slumped over, alone and unnoticed, in a darkened parking lot? Or would he have had his overdose reversed by the skilled hands of a medical professional, in a brightly lit room, devoid of stigma and shame? Would my friend still be alive?

Current Indiana legislation is not reducing nor containing the devastating effects of substance use disorder. In the next decade, if practitioners and policymakers are to get serious about mitigating the consequences of substance use disorder and are to commit to prioritizing mortality and morbidity reduction over unproductive and unnecessarily harmful criminalization, they are going to have to implement the creation of safe consumption sites. Indiana is poised to become a national public health leader, and it can pioneer a path forward to a future where individuals can have quality and quantity of life with and beyond substance use disorder. Now is the time for Indiana lawmakers to take up this mantle of change.

184. Mitch Metcalf, ShowBuzzDaily Wednesday Network Scorecard - 1.15.2020, SHOwBuZzDAILY (Jan. 16, 2020), http://www.showbuzzdaily.com/articles/the-sked-wednesdaynetwork-scorecard-1-15-2020.html [https://perma.cc/L7NR-MKVP]

185. See Alex Welch, TV By the Numbers Tracking, TV BY THE NumBers, https://tvbythenumbers.zap2it.com/ [https://perma.cc/6UVN-ZNFR] (last visited July 25, 2020). 